\title{
The Impact of Vocabulary Knowledge on the Reading Comprehension of Saudi EFL Learners
}

\author{
Fadi Al-Khasawneh \\ King Khalid University
}

\begin{abstract}
Correspondence regarding this article should be addressed to Fadi Al-Khasawneh, King Khalid University, P.O.Box: 960, Asir - Abha, Saudi Arabia, 61421.E-mail: falkhasoneh@kku.edu.sa
\end{abstract}

\begin{abstract}
Vocabulary knowledge is the building block of learning a second language and the degree of success for learning any language depends on the amount of vocabulary a learner possesses. Vocabulary knowledge contributes to mastering language skills (reading, listening, writing, and speaking). Therefore, the present study aims at determining the role of vocabulary size in reading comprehension among Saudi EFL learners. The participants of this study included 64 male students who studied at the first level in the academic year 2018/2019 at King Khalid University. Both the Vocabulary Size Test developed by (Schmitt et al.) and reading comprehension test taken from the TOEFL preparation manual were used to collect the necessary data for the study. The results of the study revealed that the overall vocabulary size of Saudi EFL learners was 2025 word families. This amount helps students to comprehend $90 \%$ of written texts as pointed out by many researchers in this field. The results also showed a significant relationship between vocabulary size and reading comprehension. Vocabulary knowledge is an important predictor for comprehending written texts. The study provides some implications for educational stakeholders such as putting more emphasis on teaching vocabulary and using different teaching strategies that assist in the acquisition of vocabulary in general and academic vocabulary in particular.
\end{abstract}

Keywords: vocabulary knowledge; vocabulary depth; vocabulary breadth; reading comprehension; Saudi EFL learners

\section{Introduction}

Vocabulary knowledge performs a significant role in the process of language learning/acquisition and cannot be neglected in second or foreign language research (Nouri \& Zerhouni, 2016). Learners of English as a foreign language are aware that their limited vocabulary knowledge might cause serious problems in language communication. This lexical restriction bans language comprehension as well as language production (Nation, 2001). Success in an academic environment and language proficiency are highly related to vocabulary knowledge (Adamson, 1993; Collier, 1989). Lexical knowledge is a very important element in improving proficiency in the four language skills (Bernhardt, 2005). The role of lexical knowledge in reading comprehension has been one of the major interests in foreign language research for the last two decades. Vocabulary knowledge and reading comprehension are highly related since lexical knowledge can assist foreign language learners in grasping the meaning of written texts. In addition, reading may help in developing learners' lexicons (Nation, 2001).

Cooper (1984) depicts vocabulary knowledge as the key component for successfully reading English paragraphs and texts, while Laufer (1997, p.20) points out that "no text comprehension is possible, either in one's native language or in a foreign language, without understanding the text's vocabulary". He also indicates that the low possibility of comprehending a text relates heavily to the high percentage of obscure vocabulary. Vocabulary knowledge plays an important role in predicting reading performance. Laufer \& Ravenhorst-Kalovski (2010) compared lexical coverage, vocabulary size, and reading scores on the English Psychometric Tests, and concluded that an adequate level of reading comprehension is possible at an optimal lexical coverage of $98 \%$ (or 8000 word 
families). Yorio (1971) surveyed language learners regarding the main barriers to reading comprehension. The students stated that insufficient vocabulary was the main obstacle they faced in reading comprehension.

Reading is a prime source for getting more knowledge in all areas of study. Students in higher education are expected to read thoroughly in English in their area of study as it is internationally recognized as the medium of instruction in most fields of study. Carrell \& Grabe (2002) emphasized the vital role of reading in language learning; they affirmed the necessity of becoming a good reader. They view reading as one of the most important skills people need in international and multicultural settings, academic learning, and self-study situations. Reading is considered the most important skill for university students to master in order to obtain knowledge in their own discipline (Carrell \& Grabe, 2002).

However, students are likely to face difficulties while reading in English (Nouri \& Zerhouni, 2016). One reason for those difficulties is attributed to the students' ignorance of the efficient strategies they need to help them with reading comprehension. Another reason is that students are unaware of systematic approaches for confronting vocabulary vagueness. Students rely heavily on context in order to understand the meaning of words and this indicates poor reading comprehension skills (Nouri \& Zerhouni, 2016). Therefore, the current study aims at examining the role of vocabulary knowledge on the reading comprehension of Saudi EFL learners at King Khalid University.

\section{Literature Review}

\section{Vocabulary Knowledge}

The process of how vocabulary learning takes place is still unclear as it requires various components of knowing a word, taking into consideration that the process of learning vocabulary is gradual in nature leading to continuity (Schmitt, 2000). The accurate use of words can be achieved through the knowledge of the words' pronunciation and spelling; however, it is clear that the real knowledge of words goes beyond these two aspects (Schmitt, 2008). Firth (1957) stated, "You shall know the word by the company it keeps" (p.11). The intended message of Firth's citation here is to classify words not only on the basis of their meanings, but also on the basis of their cooccurrence with other words. Word collocation includes the distribution of word uses and senses, comparing the use of synonymous words, and dictionary definitions. Investigating the use of synonymous distribution enables learners to determine the contextual preferences associated with other collocates (Firth, 1957).

Nation (2001) provides a comprehensive framework of the information that is necessary to improve word use at different levels. The information consists of three components: form, meaning, and use. Each class encompasses three different aspects of knowing a word, in which he also split the knowledge of words into two types: receptive and productive knowledge. These components and sub-components are made to enable learners to differentiate their capabilities to receive language input through reading or listening and understand it. In addition, the aforementioned components help to distinguish the learners' ability to produce oral or written words in an appropriate context, utilizing the proper spelling and pronunciation. The 'form' aspect involves the written and spoken knowledge that learners should take into consideration when learning new words. The aspect of 'meaning' includes words' meanings, concepts, referents, and the association of words. The aspect of 'use' covers the grammatical functions of words, their collocations, and their use restrictions. The following table illustrates Nation's framework (2001) regarding vocabulary knowledge.

As illustrated in Table 1, Nation (2001) classified vocabulary knowledge into 18 questions grouped into three categories, in which each category contains receptive and productive aspects. The framework defines vocabulary knowledge from different perspectives: pragmatic, semantic, and morphological perspectives and it shows that all of the aspects are closely interrelated. For instance, the meaning of a word could be derived from the context or the form of that word $(\mathrm{Gu}, 2017)$. However, Nation realizes that this framework is incomplete and needs modification. He indicates the difficulty of measuring vocabulary knowledge by only using this classification. He also added that the aspects of this classification are interrelated with each other, which makes differentiating between certain words difficult. 
Table 1

Components of vocabulary knowledge (Nation, 2001, p. 27)

\begin{tabular}{llll}
\hline Form & Spoken & $\mathrm{R}$ & What does the word sound like? \\
& $\mathrm{P}$ & How is the word pronounced? \\
& $\mathrm{R}$ & What does the word look like? \\
& $\mathrm{P}$ & How is the word written and spelled? \\
& $\mathrm{R}$ & What parts are recognizable in this word? \\
& $\mathrm{P}$ & What words parts are needed to express meaning? \\
\hline Feaning & $\mathrm{R}$ & What meaning does this word form signal? \\
& Form and Meaning & $\mathrm{P}$ & What word form can be used to express this meaning? \\
& $\mathrm{R}$ & What is included in the concept? \\
& $\mathrm{P}$ & What items can the concept refer to? \\
& $\mathrm{R}$ & What others words does this word make us think of? \\
& $\mathrm{P}$ & What other words could we use instead of this one? \\
\hline Use & $\mathrm{R}$ & In what patterns does the word occur? \\
& $\mathrm{P}$ & In what patterns must we use this word? \\
& $\mathrm{R}$ & What words or types of word occur with this one? \\
& $\mathrm{P}$ & What types of words must we use with this one? \\
& $\mathrm{R}$ & Where, when and how often would we meet this word? \\
& $\mathrm{P}$ & Where, when and how often can we use this word? \\
\hline
\end{tabular}

Note: $\mathrm{R}=$ receptive, $\mathrm{P}=$ productive

\section{Vocabulary Size}

Vocabulary size refers to the amount of vocabulary needed to understand and use the language (Karakoce \& Kose, 2017). Language learners need to expand their vocabulary size since "vocabulary is a continually changing entity with new words and new uses of old words being added and old words failing into disuse" (Nation \& Waring, 1997, p. 6). There is no accurate number of words to be known for native speakers or language learners since the number of words is continuously changed (Karakoce \& Kose, 2017). Learning high-frequency words is one of the vocabulary challenges facing EFL learners. In order to help learners overcome this, West (1953) created a word list known as the General Service List (GSL). GSL words were obtained from a 2.5 millionword corpus. West's selection of those words was primarily based on frequency, assuming that these words are the most essential words for foreign language learners. The selection of those words has also taken into consideration the words' universality (words are that are used across countries where English is the primary medium of communication), utility (words that cover a broad range of genres), and usefulness (words that are useful when attempting to define other lexical items) of the words selected (Gilner, 2011). Other researchers have turned to pedagogical word lists to help learners prioritize their vocabulary learning. Many attempts have been made to create academic word lists. Campion \& Elley (1971) and Praninskas (1972) created academic word lists based on small corpora, in which they counted words by hand. Ghadessy (1979) devised an academic word lists based on notes made in textbooks by students, indicating words they faced for the first time. Xue \& Nation (1984) used the lists from the aforementioned studies and created a large-scale academic word list, which they called the University Word List (UWL). This list was widely used for several years in a variety of teaching and research contexts. Coxhead (2000) used a more representative list of academic words based on the principles of corpus linguistics. She selected academic words representing a wide variety of academic disciplines, taking into consideration the different linguistic features that may differ across those disciplines. This large corpus has been divided into roughly equal sections to calculate the range of academic vocabulary across the entire corpus, and then the size of the corpus is considered. The researchers who created small-scale corpora (Campion \& Elley, 1971; Ghadessy, 1979; Praninskas, 1972) included between 300,000 to 500,000 words due to manual word counts, while Coxhead's (2000) scale included around 875,000 words across four disciplines (arts, science, law, and commerce). 
Goulden, Read \& Nation (1990) pointed out that a native speaker of English would have around 17,000 word families. Adolphs \& Schmitt (2004) indicated that foreign language learners need to have at least 2000-3000 word families to understand and use $90-94 \%$ of the language; while Nation (2006) claims that language learners need around 6000-7000 word families to comprehend the target language. Gungor \& Yalyli (2016) suggest that learners need 8000 words to comprehend texts, and this is supported by Nation's (2006) claim that it is adequate quantity to read a newspaper. Laufer (1997) suggests 5000 word families in order for EFL learners to read texts; and to reach a native-like level, learners need to have 15,000-20,000 word families (Nation, 2001).

Schmitt (2008) suggests that the previously mentioned figures include different word forms such as the root, the word inflections, and the word derivations. To explain, a vocabulary of 6000 word families involves knowing 28,015 individual words, while 8000 word families entails knowing 34,660 words (Nation, 2006). The threshold of complete comprehension is not absolute, but it is logic to say that a limited knowledge of vocabulary leads to poor understanding of English (Karakoce \& Kose, 2017). It is worth mentioning that not all words are equally beneficial in vocabulary learning and the measure of a word's usefulness is word frequencies (Karakoce \& Kose, 2017). This means that the most 2000 frequent words are easier to learn compared to 10,000 low-frequency words that rarely occur in discourse (Schmitt \& Schmitt, 2012).

\section{Vocabulary Size and Reading Comprehension}

Vocabulary size seems to play a vital role in reading comprehension. Vocabulary knowledge is one of the contributing factors for comprehending reading texts (Nation \& Coady, 1988). A number of scholars and authors have emphasized the relationship between vocabulary size and reading comprehension. Zimmerman (1997) pointed out that extensive reading on various texts leads to expanding the vocabulary knowledge. Hills \& Laufer (2003) indicated that post-reading tasks that focus on target vocabulary lead to better vocabulary knowledge. Hsueh-Chao \& Nation (2001) emphasized the relationship of vocabulary knowledge on reading comprehension as well as the relationship between reading comprehension and vocabulary knowledge. In addition, many researchers and authors claim that vocabulary knowledge and reading comprehension are strongly related and several studies have confirmed such a relationship between the two (Hsueh-Chao \& Nation, 2000; Schmitt, 2000; Nation, 2001; Zhang, 2012; Karakoce \& Kose, 2017. Pringprom (2012, p.1104) stated, "Learners will have difficulty comprehending the text if their vocabulary size is far from the required threshold". It is also pivotal to remember that there are also additional factors that affect reading comprehension other than vocabulary knowledge, such as the impact of L1 transfer, individual variance, and the difficulty of texts (Thomas \& Healy, 2012).

\section{Previous Studies on Vocabulary Knowledge and Reading Comprehension}

This section highlights some studies that have been conducted on the relationship between vocabulary knowledge and reading comprehension. Karakoce \& Kose (2017) investigated the relationship between vocabulary development and reading performance among 175 students studying in an intensive language program in Anadolu University, Turkey. The researchers used a 2000-word-level receptive vocabulary knowledge test adopted from (Schmitt, Schmitt, \& Clapham, 2001), and a 2000-word-level productive vocabulary knowledge test adopted from (Laufer \& Nation, 1999) for collecting the data used in their study. The results of this study showed that the students' receptive vocabulary knowledge was higher than their productive vocabulary knowledge. The results also revealed a significant relationship between vocabulary knowledge and reading comprehension.

$\mathrm{Gu}$ (2017) explored the impact of vocabulary knowledge dimensions (i.e. breadth and depth of vocabulary knowledge on reading comprehension tasks namely standard multiple-choice questions and summary writing in the Chinese EFL context. The sample of this study included 124 English major students from Sichuan University. The author employed various measurements to investigate the students' vocabulary depth and breadth. The results of this study revealed that the breadth and depth of vocabulary knowledge contributes significantly to reading comprehension. The breadth of vocabulary knowledge had a greater impact on multiple-choice questions while vocabulary depth had a greater impact on summary writing task. This study recommends that teachers should draw more attention to vocabulary knowledge and encourage their students to improve their reading skills through expanding their vocabulary knowledge. 
Gungor \& Yayli (2016) investigated the relationship between vocabulary coverage and reading comprehension among a group of Turkish EFL learners. The sample of this study included 178 university students who completed a vocabulary checklist based on the vocabulary items of two different expository texts. The reading comprehension level was measured through two reading comprehension tests. The findings of this study revealed that their text-based vocabulary knowledge moderately correlated with reading comprehension with a relatively linear relationship between them. The findings also showed that the $98 \%$ vocabulary coverage is necessary for learners to understand academic texts, and this coverage, in fact, refers to approximately the most frequent 8000 word families based on the related studies.

Nouri \& Zerhouni (2016) conducted a study to investigate the relationship between the dimensions of vocabulary knowledge (size and depth) and students' performance in reading. The sample of this study included 32 students who are studying at the National Institute of Posts and Telecommunication in Rabat-Morocco. The researchers employed three instruments, which included a) a vocabulary size test, b) a vocabulary depth test c) and a reading comprehension test. The results disclosed a significant relationship between the size and depth of vocabulary knowledge and reading comprehension.

Anjomshoa \& Zamanian (2014) studied the role of vocabulary knowledge on EFL learners' reading comprehension. The study recruited 81 students who were studying English at Azad University of Kerman, Iran. The researchers used a questionnaire to collect the data for their study. The results of this study revealed a significant correlation between vocabulary knowledge and the students' performance in reading comprehension. The results also suggest focusing students' attention on vocabulary knowledge due to its significant contribution in comprehending reading texts.

The present study aims at achieving the following objectives: (1) Determine the vocabulary size of Saudi EFL learners; (2) Examine the relationship between vocabulary size and reading performance among Saudi EFL learners.

The present study seeks to provide answers to the following research questions: (1) What is the extent of the vocabulary size of Saudi EFL learners? (2) To what extent does vocabulary knowledge contribute to reading comprehension among Saudi EFL learners?

\section{Materials and Methods}

\section{Research Design}

The main purpose of the present study is to investigate the role of vocabulary size in reading comprehension among Saudi EFL learners. The independent variable of the study is vocabulary size whereas the dependent variable is reading comprehension. Therefore, the design of this study is correlational as it aims to investigate the relationship between two variables. The correlational design is used to investigate the relationship or correlation between variables (Arikunto, 2010). The degree of correlation between two variables is classified in the form of a correlation coefficient. Creswell (2014) states that researchers use correlational research design to describe and measure the degree of association between two variables or set of scores. This implies that researchers do not intend to manipulate the variables, but they use the correlation statistics of two or more scores.

\section{Participants}

The current study involves 64 freshmen students enrolled in the Department of English Language at King Khalid University, Abha, Saudi Arabia. The participants included male students only as the researcher conducted the study at the male campus.

The educational system in Saudi Arabia does not allow mixing between male and female students. Although they sometimes belong to the same university, male and female students are segregated and taught by professors 
of the same sex. The participants were taught English as a foreign language for six years at intermediate and secondary schools before enrolling in university programs. The participants were all native speakers of Arabic, and two tests were administered to them, Vocabulary Size Test (Schmitt et al. 2001) and Reading Comprehension Tests.

\section{Research Instruments}

Studies on investigating vocabulary size rely heavily on collecting data from tests. The current study adopted two tests to determine vocabulary size, and to investigate the relationship between vocabulary size and reading comprehension among Saudi EFL learners.

Vocabulary Size Test. The Vocabulary Size Test employed in this study was originally developed by Nation (1983) and later it was amended and revised by Schmitt et al. (2001). The modified version of the Vocabulary Size Test has proved that 30 items per level was more reliable than the 18 items found in Nation's (1983) test. This test includes four parts, which provide estimate of vocabulary size at 2000, 3000, 5000, and 10,000-word frequency levels. The first two parts (2000 and 3000-word frequency levels contain only high frequency words in English; the 5000-word frequency level falls between high-frequency words and low-frequency words; and the 10,000 -word frequency level includes low-frequency words. This vocabulary test was chosen because it reduces the guessing to one response among six choices. It also includes all the words in each group that represent the same type of word with no syntactic clues for the accurate matches (Varnaseri, 2016). This version of the test contains ten clusters in which six words and three definitions are provided. The testees are expected to match the word with its correct definition. The following is an example taken from the 2000-word frequency level:
1. Business
2. Clock
3. Horse
4. Pencil
5. Shoe
6. Wall
6__ part of a house
3 - animal with four legs
4_ something used for writing

Reading Comprehension Test. The reading comprehension test was the second instrument used in the present study. The test encompassed two reading passages and they were taken from one TOEFL preparation manual. The first passage was about British Columbia and had 117 words; and the second passage was about Rain and was 242 words in length. The two reading passages are associated with 10 multiple-choice questions, and each correct answer was assigned one point; so the maximum possible score of the reading comprehension test was 10 points. These two reading passages were chosen due to their suitability to the students' level. In addition, the content vocabulary items in the reading passages were found in the vocabulary lists in the participants' university textbooks, which represents content validity in the reading passages.

\section{Data Collection and Analysis}

Both tests (i.e. Vocabulary Size Test and Reading Comprehension Test) were piloted with a group of 10 students from outside the sample of this study. The main purpose of the pilot tests was to have an idea about the suitable time to allocate the students for completing both tests. The students needed 60 minutes to complete the vocabulary size test and 45 minutes to complete the reading comprehension test. For the main study, both tests were administered to students during their normal classes in the $13^{\text {th }}$ week of the first semester of the 2018/2019 academic year. The students had been informed about the objectives of the study and told that these two tests would not affect their total mark in the said course. Furthermore, they had been informed about the way to complete both tests and were given examples before the commencement of the official tests. The students received the reading comprehension test after they had submitted the vocabulary size test. Statistical Package for Social Sciences (SPSS) version 18 was used to analyze the data of the present study. Descriptive statistics were utilized to show the vocabulary size of Saudi EFL learners. Pearson Correlation analyses were also employed to find any potential relationship between students' vocabulary size and reading comprehension. 


\section{Results and Discussion}

This section presents the results obtained from this research. The results are shown according to the research questions posed earlier in this study.

\section{Results Related to the First Research Question}

This section presents the results related to the first question: What is the extent of the vocabulary size of Saudi EFL learners? To answer this question, descriptive statistics were calculated to find out the size of vocabulary knowledge. Descriptive statistics of the four sections of the vocabulary size test are shown in Table 2.

Table 2

Descriptive statistics of the vocabulary size test

\begin{tabular}{lccccc}
\hline & N & Minimum & Maximum & Mean & Std. Deviation \\
\hline Level2000 & 64 & 0.00 & 8.00 & 3.33 & 2.354 \\
Level3000 & 64 & 0.00 & 8.00 & 1.18 & 1.150 \\
Level5000 & 64 & 0.00 & 8.00 & 0.89 & 1.1415 \\
Level10000 & 64 & 0.00 & 4.00 & 0.56 & 0.990 \\
Valid N (listwise) & 64 & & & & \\
\hline
\end{tabular}

The participants sat for the 2000-word level of the vocabulary size test. The mean score of this section was (3.33). This section contains 10 items and each item was awarded one point for each correct answer. The average number of known words in this section was 3 out of 10 words. This shows that the vocabulary size of students in this section was about 666 words. The participants also responded to the 3000 -word level of this test. The responses for this section of the test show a mean of (1.18); which means that the students know only 1 out of 10 words in this particular level. This indicates that the vocabulary size knowledge among the students in this level was 354 words. The students were unable to answer most of the questions in this level correctly.

Regarding the 5000-word level, the mean score of the participants was (0.89), which implies low knowledge of the words in this level. The participants' vocabulary size estimate was 445 words, which interestingly shows more knowledge compared to the 3000-word level. The last section of the vocabulary test dealt with the level of 10,000 words. The participants scored very low in this level and their mean score was $(0.56)$, which means the majority of students were unable to answer any question correctly. This mean score suggests a vocabulary size of 560 words in this level. After examining the descriptive statistics regarding the first question of this research, we can conclude that the overall vocabulary size among the students was 2025 word families.

Laufer (1997) suggests 5000 word families in order for an EFL learners to read and fully understand texts. Nation (2006) stated that learners need to know 9000 word families to cover $98 \%$ of a text when reading novels, 8000 word families when reading newspapers, 7000 word families to understand most spoken words in English, and 6000 word families for understanding most words in children's movies. Nation \& Beglar (2007) indicated that the vocabulary size of undergraduate non-native speakers is around 5000-6000 word families.

Nguyen and Nation (2011) found that Vietnamese third-year English major students' average vocabulary size was 6,661 English word families. In comparison, it seems that the vocabulary knowledge of the participants of the current study was far from that level. Therefore, students should be presented with vocabulary learning strategies in an attempt to foster their lexical knowledge.

\section{Results Related to the Second Research Question}

Concerning the second research question, to what extent does vocabulary knowledge contribute to reading comprehension among Saudi EFL learners? The researcher used the Pearson Correlation Test to find any significant relationships between vocabulary size and reading comprehension. The students' scores in the reading comprehension test were correlated with each vocabulary level (2000-word level, 3000-word level, 5000-word level, and 10,000-word level), and the students' scores in the overall vocabulary size knowledge test. The results of the correlation test are illustrated in Table 3. 
Table 3

Correlation between vocabulary size and reading comprehension

\begin{tabular}{|c|c|c|c|c|c|c|c|}
\hline & & RC & Level2000 & Level3000 & Level5000 & Level10,000 & VS \\
\hline \multirow[t]{3}{*}{$\mathrm{RC}$} & Pearson Correlation & 1 & $.726^{* * *}$ & $.336 * *$ & -.225 & $-.271^{*}$ & $.477^{* * *}$ \\
\hline & Sig. (2-tailed) & & .000 & .007 & .074 & .030 & .000 \\
\hline & $\mathrm{N}$ & 64 & 64 & 64 & 64 & 64 & 64 \\
\hline \multirow[t]{3}{*}{ Level2000 } & Pearson Correlation & $.726^{* * *}$ & 1 & $.404^{* * *}$ & -.101 & $-.303^{*}$ & $.739 * *$ \\
\hline & Sig. (2-tailed) & .000 & & .001 & .426 & .015 & .000 \\
\hline & $\mathrm{N}$ & 64 & 64 & 64 & 64 & 64 & 64 \\
\hline \multirow[t]{3}{*}{ Level3000 } & Pearson Correlation & $.336^{* * *}$ & $.404^{* * *}$ & 1 & -.096 & -.218 & $.667 * *$ \\
\hline & Sig. (2-tailed) & .007 & .001 & & .451 & .083 & .000 \\
\hline & $\mathrm{N}$ & 64 & 64 & 64 & 64 & 64 & 64 \\
\hline \multirow[t]{3}{*}{ Level5000 } & Pearson Correlation & $.301 * *$ & -.101 & -.096 & 1 & .237 & $.378^{* * *}$ \\
\hline & Sig. (2-tailed) & .004 & .426 & .451 & & .059 & .002 \\
\hline & $\mathrm{N}$ & 64 & 64 & 64 & 64 & 64 & 64 \\
\hline \multirow[t]{3}{*}{ Level10000 } & Pearson Correlation & $.271^{*}$ & $-.303^{*}$ & -.218 & .237 & 1 & .045 \\
\hline & Sig. (2-tailed) & .003 & .015 & .083 & .059 & & .725 \\
\hline & $\mathrm{N}$ & 64 & 64 & 64 & 64 & 64 & 64 \\
\hline \multirow[t]{3}{*}{ VS } & Pearson Correlation & $.477^{* * *}$ & $.739 * *$ & $.667 * *$ & $.378 * *$ & .045 & 1 \\
\hline & Sig. (2-tailed) & .000 & .000 & .000 & .002 & .725 & \\
\hline & $\mathrm{N}$ & 64 & 64 & 64 & 64 & 64 & 64 \\
\hline
\end{tabular}

As shown in Table 3, there was a significant correlation between reading comprehension and vocabulary size at the 2000-word level, $\mathrm{r}=.726, p<.001$. There was also a significant correlation between reading comprehension and vocabulary size at the 3000,5000 , and 10,000-word levels, $r=.336$ (3000-word level), $r=.301$ (5000-word level), $\mathrm{r}=.271$ (10,000-word level) $p<.001$. Concerning the relationship between the reading comprehension test and overall vocabulary size test, the results showed a significant correlation between them $\mathrm{r}=.477, \mathrm{p}<.001$. It can be inferred from these results that the more vocabulary students know, the better they perform in reading comprehension tests. The present results concur with the findings of some prior studies on this topic (Karakoce \& Kose, 2017; Gu, 2017; Nouri and Zerhouni, 2016; Anjomshoa \& Zamanian, 2014). The consistent results regarding the relationship between vocabulary size and reading comprehension affirm the important role of vocabulary knowledge in reading comprehension. Vocabulary size and reading comprehension are interrelated since reading contributes to vocabulary knowledge and vocabulary knowledge assists in understanding written texts (Nation, 2001; Anjomshoa \& Zamanian, 2014).

The previous research on the relationship between vocabulary size and reading comprehension has revealed that vocabulary knowledge is highly correlated with L2 reading comprehension (Droop \& Verhoeven, 2003; Eskey, 2005; Hsueh-Chao \& Nation, 2000; Pike, 1979; Qian, 2002; Schmitt, 2000; Schoonen, Hulstijn, \& Bossers, 1998; Stahl, 2003). Subsequently, the findings of the present study are expected to provide a comprehensive image of the relationship between the vocabulary size and reading comprehension of tertiary level Saudi EFL learners. The correlation value shows a positive relationship between the two variables. To reach a deeper comprehension level, readers are required to have some reading skills such as making coherent connection between ideas, inferencing, understanding the author's rationale, and activating their background knowledge (Graesser, 2007). Hsueh-Chao \& Nation (2000) suggested that vocabulary knowledge is a necessary prerequisite for reading comprehension. Learners need to know at least $98 \%$ of the content words to comprehend a text, which does not mean that learners can understand the text 100\% (Schmitt et.al, 2011). Laufer (1989) states that below 95\% coverage does not mean that a learner cannot understand the text since several factors are involved in the understanding process. Readers could increase their understanding of a text by utilizing their background knowledge about the topic, the text type, and grammatical clues. On the other hand, understanding demonstrative/expository texts may still be a real challenge for learners. The reasons for this might be attributed to the text's organization, lack of knowledge of key terms, and the lack knowledge of the text's topic (Graesser, 2007). 


\section{Limitations of the Study}

The present study aimed at investigating the extent of vocabulary knowledge and the relationship between the vocabulary knowledge and reading comprehension of Saudi EFL learners in the southern region of Saudi Arabia. The researcher does not claim that the results are representative as regional academic differences may exist between students from different places in the Kingdom. The present study does not focus on any vocabulary acquisition problems that learners might face, but seeks to investigate the level of their vocabulary knowledge and its relationship with reading comprehension. The participants of the present study included male students only as the educational system in Saudi Arabia does not allow male and female students to be together on the same campus. This could lead to more research investigating the gender differences regarding vocabulary size and its relationship to reading comprehension. Finally, the present study used quantitative methods to elicit information concerning vocabulary size and reading comprehension achievement. Thus, qualitative studies are recommended to get in-depth understanding of Saudi teachers, students, and curriculum designers of their needs and problems regarding vocabulary acquisition and reading problems.

\section{Conclusion}

The current study reveals a positive correlation between vocabulary size and reading comprehension. Vocabulary size is considered to be an important predictor of the ability to comprehend written texts and they are strongly related. In view of the results of this study, some pedagogical implications for EFL learning and teaching can be suggested. One of the key steps that should be taken into consideration is that vocabulary teaching should surpass the superficial level. High-frequency words should be introduced deeply and in a way that learners can acquire full knowledge of the core vocabulary. In addition, teachers and students should be aware of some major aspects of learning vocabulary such as the definitions of words, synonyms, antonyms, word collocations, and semantic and pragmatic characteristics. The use of various methods of teaching are highly recommended for assisting EFL learners in enlarging their lexical knowledge. Instructors should increase their awareness of the usage of lexis in the classroom. They also should teach students how to get benefits from corpus approaches in the classroom. Accordingly, the lexical knowledge of learners can be improved, and, in turn, enhanced lexical knowledge might lead to higher levels of reading comprehension.

Furthermore, various vocabulary learning strategies should be introduced and practiced by the students in order for them to become autonomous learners. EFL teachers at Saudi universities should introduce academic vocabulary to students to enhance their lexical knowledge. EFL teachers could provide separate vocabulary classes focusing on academic vocabulary and the most frequent 2000 words. It would also be beneficial to spend extra time teaching students academic vocabulary to acquire the most frequently used academic words since knowing those words will improve the coverage of academic texts.

\section{Acknowledgement}

The author would like to express his gratitude to King Khalid University, Saudi Arabia for providing administrative and technical support.

\section{References}

Adamson, H. D. (1993). Academic competence, theory and classroom practice: Preparing ESL students for content courses. New York, NY: Longman.

Adolphs, S., \& Schmitt, N. (2003). Lexical coverage of spoken discourse. Applied Linguistics, 24(4), 425-438. https://doi.org/10.1093/applin/24.4.425

Anjomshoa, L., \& Zamanian, M. (2014). The effect of vocabulary knowledge on reading comprehension of Iranian EFL learners in Kerman Azad University. International Journal on Studies in English Language and 
Literature, 2(5), 90-95.

Arikunto, S. (2010). Research procedure: A practice approach. Jakarta, Indonesia: Rineka Cipta.

Bernhardt, E. (2005). Progress and procrastination in second language reading. Annual Review of Applied Linguistics, 25, 133-150. https://doi.org/10.1017/S0267190505000073

Campion, M., \& Elley, W. (1971). An academic vocabulary list. Wellington, New Zealand: Council for Educational Research.

Carrell, P. L., \& Grabe, W. (2002). Reading. In N. Schmitt (Ed.), An introduction to applied linguistics (pp. 233-250). London, UK: Arnold.

Collier, V. P. (1989). How long? A synthesis of research on academic achievement in a second language. TESOL Quarterly, 23(3), 509-531.

Cooper, M. (1984). Linguistic competence of practiced and unpracticed non-native readers of English. In J.C. Alderson \& A.H. Urquhart (Eds.), Reading in a foreign language (pp. 122-138). New York, NY: Longman.

Coxhead, A. (2011). The Academic Word List 10 years on: Research and teaching implications. TESOL Quarterly, 45(2), 355-362. https://doi.org/10.5054/tq.2011.254528

Creswell, J. W. (2014). Research design: Qualitative, quantitative and mixed methods approaches (4th ed.). London, UK: Sage Publications Ltd.

Droop, M., \& Verhoeven, L. (2003). Language proficiency and reading ability in the first and second language learners. Reading Research Quarterly, 38(1), 78-103. https://doi.org/10.1598/RRQ.38.1.4.

Eskey, D. E. (2005). Reading in a second language. In E. Hinkel (Ed.), Handbook of research in second language teaching and learning (pp. 563-580). New Jersey, NJ: Lawrence Erlbaum. https://doi.org/10.1093/ oxfordhb/9780195384253.013.0006

Firth, J.R. (1957). Papers in Linguistics 1934-1951. Oxford, UK: Oxford University Press.

Ghadessy, P. (1979). Frequency counts, words lists, and materials preparation: A new approach. English Teaching Forum, 17, 24-27.

Gilner, L. (2011). A primer on the general service list. Reading in a Foreign Language, 23(1), 65.

Goulden, R., Nation, I. S. P., \& Read, J. (1990). How large can a receptive vocabulary be? Applied Linguistics, 11(4), 341-363.

Graesser, A. C. (2007). An introduction to strategic reading comprehension. In D. S. McNamara (Ed.), Reading comprehension strategies: Theories, interventions and technologies (pp. 3-26). New York, NY: Lawrence Erlbaum Associates.

Güngör, F., \& Yaylı, D. (2016). The interplay between text-based vocabulary size and reading comprehension of Turkish EFL learners. Educational Sciences: Theory \& Practice, 16, 1171-1188. https://doi.org/10.12738/ estp.2016.4.0078

$\mathrm{Gu}$, T. (2017). The Effect of Vocabulary Knowledge on Chinese English Learners' Reading Comprehension. International Journal of English Linguistics, 7(4), 45-55. https://doi.org/10.5539/ijel.v7n4p45

Hills, M., \& Laufer, B. (2003). Type of task, time-on-task and electronic dictionaries in incidental vocabulary acquisition. International Review of Applied Linguistics, 41(2), 87-106. https://doi.org/10.1515/iral.2003.007.

Hsueh-Chao, M. H., \& Nation, P. (2000). Unknown vocabulary density and reading comprehension. Reading in a Foreign Language, 13(1), 403-430.

Karakoc, D., \& Kose, G. (2017). The impact of vocabulary knowledge on reading, writing and proficiency scores of EFL learners. Journal of Language and Linguistic Studies, 13(1), 352-378.

Kennedy, G. (1998). An introduction to corpus linguistics. London, UK: Longman.

Laufer, B. (1989). What percentage of text-lexis is essential for comprehension? In C. Lauren \& M. Nordman (Eds.), Special language: Form human thinking to thinking machines (pp. 316-323). Clevedon, UK: Multilingual Matters.

Laufer, B. (1997). The Lexical plight in second language reading: Words you don't know, words you think you know, and words you can't guess. In J. Coady \& T. Huckin (Eds.), Second language vocabulary acquisition (pp. 20-34). Cambridge: UK, Cambridge University Press.

Laufer, B., \& Nation, P. (1999). A vocabulary-size test of controlled productive ability. Language Testing, 16(1), 33-51.

Laufer, B., \& Ravenhorst-Kalovski, G. C. (2010). Lexical threshold revisited: Lexical text coverage, learners' vocabulary size and reading comprehension. Reading in a Foreign Language, 22(1), 15-30.

Nation, P. (1983). Testing and teaching vocabulary. Guidelines, 5(1), 12-25.

Nation, P. (2001). Learning vocabulary in another language. Cambridge, UK: Cambridge University Press.

Nation, P. (2006). How large a vocabulary is needed for reading and listening? Canadian Modern Language Review, 63(1), 59-82. https://doi.org/10.3138/cmlr.63.1.59. 
Nation, P., \& Coady. J. (1988). Vocabulary and reading. In R. Carter \& M. McCarthy (Eds.), Vocabulary and language teaching (pp. 97-110). New York, NY: Longman.

Nation, P., \& Waring, R. (1997). Vocabulary size, text coverage and word lists. In N. Schmitt \& M. McCarthy (Eds.), Vocabulary, description, acquisition and pedagogy (pp. 6-19). New York, NY: Cambridge University Press.

Nation, I. S. P., \& Beglar, D. (2007). A vocabulary size test. The Language Teacher, 31(7), 9-13.

Nguyen, L. T. C., \& Nation, P. (2011). A bilingual vocabulary size test of English for Vietnamese learners. RELC Journal, 42(1), 86-99. https://doi.org/10.1177/0033688210390264

Nouri, N., \& Zerhouni, B. (2016). The relationship between vocabulary knowledge and reading comprehension among MoroccanEFLlearners. Journal ofHumanities and Social Science,21(10), 19-26.https://doi.10.9790/08372110051926.

Pike, L. (1979). An evaluation of alternative item formats for testing English as a second language. TOEFL (Research Reports No. 2). Princeton, NJ: Educational Testing Service.

Praninskas, J. (1972). American university word list. London, UK: Longman.

Pringprom, P. (2012). Exploring relationship between students" vocabulary breadth and their reading proficiency. US-China Foreign Language, 10(4), 1098-1105.

Qian, D. D. (2002). Investigating the relationship between vocabulary knowledge and academic reading performance: An assessment perspective. Language Learning, 52(3), 513-536. https://doi.org/10.1111/14679922.00193

Schmitt, N. (2000). Vocabulary in language teaching. Cambridge, UK: Cambridge University Press.

Schmitt, N. (2008). Instructed second language vocabulary learning. Language Teaching Research, 12(3), 329363. https://doi.org/10.1177/1362168808089921.

Schmitt, N., Schmitt, D., \& Clapham, C. (2001). Developing and exploring the behavior of two new versions of the Vocabulary Levels Test. Language Testing, 18(1), 55-88. https://doi.org/10.1177/026553220101800103

Schmitt, N., Jiang, X., \& Grabe, W. (2011). The percentage of words known in a text and reading comprehension. The Modern Language Journal, 95, 26-43. https://doi.org/10.1111/j.1540-4781.2011.01146.x

Schmitt, N., \& Schmitt, D. (2012). A reassessment of frequency and vocabulary size in L2 vocabulary teaching. Language Teaching, 47(04), 484-503. https://doi.org/10.1017/S0261444812000018

Schoonen, R., Hulstijn, J., \& Bossers, B. (1998). Metacognitive and language-specific knowledge in native and foreign language reading comprehension: An empirical study among Dutch students in grades 6, 8, and 10. Language Learning, 48, 71-106.

Stahl, S. A. (2003). Vocabulary and readability: How knowing word meanings affects comprehension. Topics in Language Disorders, 23(3), 241-247. http://dx.doi.org/10.1097/00011363-200307000-00009

Thomas, K. H., \& Healy, A. F. (2012). A comparison of rereading benefits in first and second language reading. Language Learning, 62, 198-235. https://doi.org/10.1111/j.1467-9922.2011.00688.x

Varnaseri, M. (2016). The relationship between depth and breadth of vocabulary knowledge and writing performance of Iranian MA students of TEFL. Modern Journal of Language Teaching Methods, 6(2), 544-545.

West, M. (1953). A General service list of English words. London, UK: Longman, Green \& Co.

Xue, G., \& Nation, P. (1984). A university word list. Language Learning and Communication, 3, 215-229.

Yorio, C. (1971). Some sources of reading problems for foreign language learners. Language Learning, 21, 107115.

Zhang, D. (2012). Vocabulary and grammar knowledge in second language reading comprehension: A structural equation modeling study. The Modern Language Journal, 96(4), 558-575. https://doi.org/10.2307/23361716 